\title{
Citizen CyberScience - New Directions and Opportunities for Human Computation
}

GREG NEWMAN, Natural Resource Ecology Laboratory, Colorado State University

"There are already hundreds of thousands of people actively contributing to citizen cyberscience - we want to reach tens of millions." - Francois Grey, Citizen Cyberscience Centre Coordinator

"Citizen Cyberscience offers people around the world the opportunity to contribute to cuttingedge scientific research that may be of fundamental significance, as well as having applications relevant to their own lives." - John Ellis, CERN and James Clerk Maxwell Professor of Theoretical Physics at Kings College London

"Citizen Cyberscience has great potential not only for scientific researchers, but also for those working in the humanities and cultural heritage." - Mark Hedges, Deputy Director of the Centre for e-Research at King's College London

"The power of the Internet and the growing public availability of scientific and other data have made possible the involvement of a wide variety of communities and citizens in a range of activities that... break new ground in public awareness and direct participation in important areas of scientific research." - Professor John Darlington, Director of the London e-Science Centre

\section{INTRODUCTION}

Have you ever heard glowing reviews of the next best thing - a tool that will solve all problems and then immediately become skeptical? Why are we to believe such claims and adopt new innovations? The proclamations above regarding citizen cyberscience starting this special issue originate from participants attending and/or discussing the third annual Citizen Cyberscience Summit, held at the Royal Geographical Society and University College, London, February 20th and 22nd, 2014. But, what is citizen cyberscience? Is this phenomenon worthy of such reviews? What current applications illustrate the benefits of citizen cyberscience for research and public 
engagement and why? This special issue sheds light on these questions by providing examples of citizen cyberscience; offering a snapshot of the myriad diverse approaches, topics, and projects covered at the Summit; and setting a course for the future. But first, a little background.

The Citizen Cyberscience Centre (CCC) is a partnership to promote the use of citizen science on the Web as an appropriate low-cost technology for researchers in developing regions. The Centre emphasizes collaboration between academia and international research organizations to create practical, open source software tools for Web-based public participation in science. The CCC conceived of the notion of citizen cyberscience and the idea of hosting an annual summit dedicated to the topic - the most recent of which was the 3rd annual summit summarized herein. The concept of citizen cyberscience has been described as "...a grass-roots movement which challenges the assumption that only professional [scientists] can do science. Given the right tools and incentives, and some online training, millions of enthusiastic volunteers can make a real difference, contributing to significant scientific discoveries" - Pierre Spierer, Vice Director for Research at the University of Geneva (as quoted in PC Magazine ${ }^{1}$ ). Citizen cyberscience has been said to be sub-categorized as volunteered computing, volunteered thinking, and participatory sensing (Haklay 2013). But how does citizen cyberscience differ from other forms of public scientific engagement? How can it contribute to human computation?

\section{CITIZEN CYBERSCIENCE}

In my own view, citizen cyberscience is online participation in scientific research by members of the public. The key here is to see the diverse approaches this phenomenon employs and the enormous variety of topics it addresses, yet also recognize that the narrow focus includes only those activities conducted, at least partly, online. The breadth of approaches and variety of topics covered by citizen cyberscience is exemplified in the articles within this special issue. From linguistics (Crane et al, this issue) to archaeology (Bevan et al., this issue) and from biodiversity (Gärdenfors et al., this issue) to psychology (Jennett et al., this issue), we can immediately see the wealth of opportunity citizen cyberscience offers the world and scientific research. Etymologically, the term "citizen" stems from the Latin term "civitas" and the Anglo-Norman French term "citezein" (city) referring to an inhabitant of a city whereas "cyber" is a prefix derived from "cybernetic," coming from the Greek adjective $\kappa \nu \beta \varepsilon \rho v \eta \tau$ steering or governing (Liddell and Scott, Greek-English Lexicon); it is a common prefix used in Information Technology, Computers and the Internet (Straubhaar and LaRose 2004). Taken together, we can see "citizen cyberscience" as "public online science" or science conducted online by members of a city or inhabited place, which in this case is the global community of Internet users.

${ }^{1}$ PC magazine; August 11, 2011; http://www.pcmag.com/article2/0,2817,2390902,00.asp 
If citizen cyberscience is online science by members of the public, then how does this concept relate to human computation, crowdsourcing, social information processing, and collective intelligence? Conceptually, possible relationships of citizen cyberscience (online citizen science) and domains such as human computation, social information processing, and collective intelligence are shown in Figure 1, specifically illustrating overlapping relationships and key dimensions of human computation (Quinn and Bederson 2011; Michelucci 2013a), crowdsourcing (Estelles-Arolas and Gonzalez-Ladron-de-Guevara 2012), and citizen cyberscience. Like citizen cyberscience, human computation can mean many things to many people - from "using a computer to combine answers from many people into a single best answer" to "taking a problem that is too big for any one person and splitting it into smaller, more manageable pieces that can be delegated to many people" (Michelucci 2013b). It can include the analysis of human behavior in social networks to understand the spread of ideas and/or predict outcomes, extend the notion of computing systems to include human agents, encompass machinemediated computation by groups of individuals, and leverage aggregate analytic results by groups resulting from individuals' information processing (Michelucci 2013b). Not all human computation is science, however, given that the tasks and computations achieved may or may not be contributing directly to the advancement of science. Similarly, not all crowdsourcing initiatives are citizen cyberscience for a similar reason - lacking a direct tie to scientific outcomes (Figure 1). Although it could be argued that most crowdsourcing initiatives benefit from collective intelligence (Estelles-Arolas and Gonzalez-Ladron-de-Guevara 2012), some human computation tasks and analyses may be done in isolation by individual humans rather than by groups that may or may not be socially interacting (Figure 1). Regardless of definition and subtle nuances, citizen cyberscience and human computation are clearly inextricably related. 


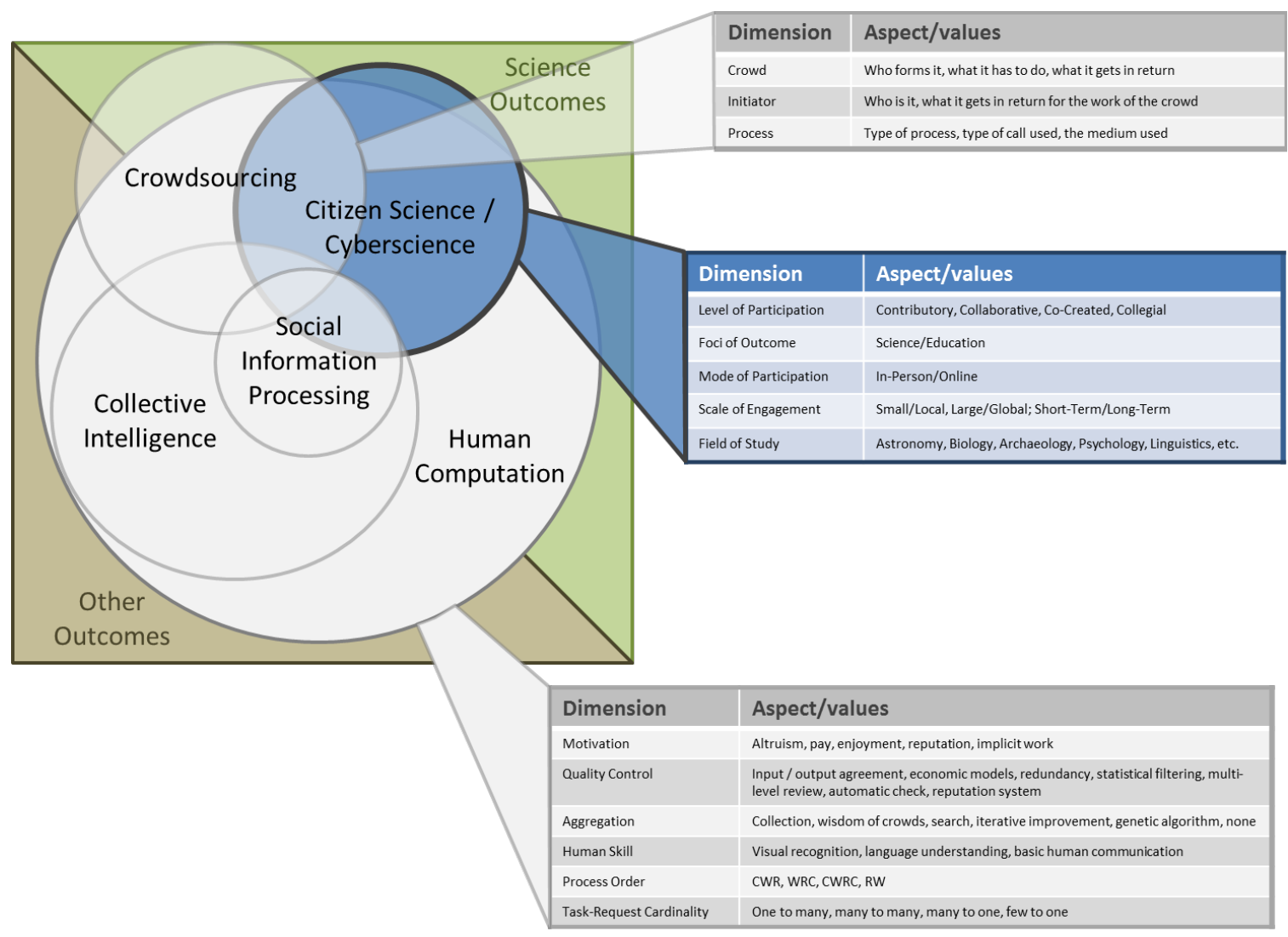

Figure 1 - Conceptual Venn diagram illustrating potential relationships between human computation, crowdsourcing, social information processing, collective intelligence, and citizen science/cyberscience within scientific and other outcomes. Various dimensions and aspects of crowdsourcing, human computation, and citizen science/cyberscience are also shown; Adapted from Quinn and Bederson (2011) and definitions from Michelucci (2013a).

\section{RELATIONSHIPS TO HUMAN COMPUTATION}

To better illustrate the relationships between citizen cyberscience and human computation, we can draw upon several case studies within this special issue (Table 1). Like the varied dimensions of citizen cyberscience demonstrated in the articles in this special issue, the type of information processing or cognition involved by those humans participating also varies (Table 1). For example, the pattern recognition abilities of ForestWatchers participants use smartphones, tablets and notebooks to access a Web interface and review satellite images of forested regions, confirm whether automatic assignments of forested and deforested regions are correct, and serve as participatory sensing agents to contribute photos of forested areas. Conversely, the social network 
analyses of Errordiary participants represent a completely different avenue of human computation research in which participants report mistakes/errors they make on a daily basis themselves - in this way they are reporting data that arise from their own personal characteristics rather than those of the physical environment and their information processing stems from their own reflection about how how they may fit into the wider social world. The ability of participants to identify wildlife (e.g., BOKUroadkill) and many other species (e.g., Swedish LifeWatch) presents several human computation tasks to participants mostly centered upon species identification related tasks such as perceptual tasks, pattern recognition, classification tasks, inductive top-down reasoning about the likelihood that the species might be of a certain type, and a reliance of worldly knowledge of species characteristics (Table 1). It may be a useful exercise to the HCliterate reader to consider how each of the projects described in this special issue include elements of human computation.

\begin{tabular}{|c|c|c|c|c|c|c|c|}
\hline Project/Authors & $\begin{array}{l}\text { Level of } \\
\text { Participation }\end{array}$ & $\begin{array}{l}\text { Foci of } \\
\text { Outcome }\end{array}$ & $\begin{array}{l}\text { Mode of } \\
\text { Participation }\end{array}$ & Scale & $\begin{array}{l}\text { Field of } \\
\text { Study }\end{array}$ & $\begin{array}{l}\text { Human } \\
\text { Contribution }\end{array}$ & $\begin{array}{l}\text { Machine } \\
\text { Contribution }\end{array}$ \\
\hline $\begin{array}{l}\text { SOCIENTIZE: Cell Spotting, Sun4All, } \\
\text { MindPaths, SavingEnergy@Home } \\
\text { Silva (2014; this issue) }\end{array}$ & $\begin{array}{l}\text { Diverse, } \\
\text { Collaborative }\end{array}$ & Diverse & Diverse & Diverse & Diverse & $\begin{array}{l}\text { Optimization, pattern } \\
\text { recognition, similarity } \\
\text { judgment, deduction, } \\
\text { discrimination }\end{array}$ & $\begin{array}{l}\text { Persistent storage, } \\
\text { visualization, image } \\
\text { filtering, calculations, data } \\
\text { integrity, counting }\end{array}$ \\
\hline $\begin{array}{l}\text { ForestWatchers } \\
\text { Pacheco da Luz et al. (2014; this } \\
\text { issue) }\end{array}$ & Contributory & Science & Online & Global & Ecology & $\begin{array}{l}\text { Classification, pattern } \\
\text { recognition, deductive } \\
\text { reasoning, participatory } \\
\text { sensing, visual perception }\end{array}$ & $\begin{array}{l}\text { Persistent storage, } \\
\text { visualization, image } \\
\text { filtering, calculations, } \\
\text { counting, image processing }\end{array}$ \\
\hline $\begin{array}{l}\text { Swedish LifeWatch } \\
\text { Gärdenfors et al. (2014; this issue) }\end{array}$ & Contributory & Science & Online \& In Person & Regional & Biodiversity & $\begin{array}{l}\text { Species identification: } \\
\text { classification, pattern } \\
\text { recognition, deductive } \\
\text { reasoning, sensing }\end{array}$ & $\begin{array}{l}\text { Geo-referencing, geo- } \\
\text { location services, } \\
\text { calculations, persistent } \\
\text { storage, visualization, } \\
\text { image processing }\end{array}$ \\
\hline $\begin{array}{l}\text { BOKUroadkill } \\
\text { Heigl and Zaller (2014; this issue) }\end{array}$ & Contributory & Education & Online \& In Person & Regional & Ecology & $\begin{array}{l}\text { Species identification: } \\
\text { classification, pattern } \\
\text { recognition, deductive } \\
\text { reasoning, sensing }\end{array}$ & $\begin{array}{l}\text { Geo-referencing, geo- } \\
\text { location services, } \\
\text { calculations, persistent } \\
\text { storage, visualization }\end{array}$ \\
\hline $\begin{array}{l}\text { MicroPasts } \\
\text { Bevan et al. (2014; this issue) }\end{array}$ & Collaborative & $\begin{array}{l}\text { Science, and } \\
\text { Education }\end{array}$ & Online & Global & Archaeology & $\begin{array}{l}\text { Transcription, geo-referencing, } \\
\text { pattern recognition, outline } \\
\text { masking (3D modeling) }\end{array}$ & $\begin{array}{l}\text { Scanning, image } \\
\text { processing, geo- } \\
\text { referencing, persistent } \\
\text { storage, 3D rendering }\end{array}$ \\
\hline $\begin{array}{l}\text { Errordiary } \\
\text { Jennett et al. (2014; this issue) }\end{array}$ & Contributory & $\begin{array}{l}\text { Science, and } \\
\text { Education }\end{array}$ & Online & Global & Psychology & $\begin{array}{l}\text { Self reflection, participatory } \\
\text { sensing, cognitive resilience }\end{array}$ & $\begin{array}{l}\text { Persistent storage, } \\
\text { searching, string processing }\end{array}$ \\
\hline $\begin{array}{l}\text { Quantum Moves } \\
\text { Lieberoth et al. (2014; this issue) }\end{array}$ & Contributory & Science & Online & Global & Physics & $\begin{array}{l}\text { Hybrid optimization, collective } \\
\text { intelligence, quantum } \\
\text { optimization, state-space } \\
\text { reduction, search tree pruning }\end{array}$ & $\begin{array}{l}\text { Process execution, } \\
\text { calculation, artificial } \\
\text { intelligence, meta-system } \\
\text { delivery }\end{array}$ \\
\hline $\begin{array}{l}\text { Cost of Quality (CoQ) Models } \\
\text { Iren and Bilgen (2014; this issue) }\end{array}$ & Diverse & Data Quality & NA & Diverse & Diverse & $\begin{array}{l}\text { Optimization (costs versus } \\
\text { quality) }\end{array}$ & Data integrity \\
\hline
\end{tabular}

Table 1 - The various citizen cyberscience projects presented in this special issue, including their levels of participation, foci of outcomes, mode of participation, scale, field of study, human contribution(s), and machine contribution(s). 


\section{CONCLUSION: NEW DIRECTIONS AND OPPORTUNITIES FOR CITIZEN CYBERSCIENCE AND HUMAN COMPUTATION}

Citizen Cyberscience offers human computation many opportunities. Some citizen science projects introduce new human computation techniques or engagement modalities, thus directly contributing to a growing body of human computation methods. In this way we can see citizen science as applied human computation, a platform for human computation research, and a body of work that may innovate in the human computation space. As an example, citizen science often generates platforms for citizen engagement that can be used in human computation research. Many such platforms are detailed in the articles within this special issue. Most existing platforms tend to be either single-application, single-subject (e.g., eBird) or multi-application, multi subject (e.g., CitSci.org; see Newman et al. 2011, iNaturalist, Liquid.io, SENSR, and CrowdCrafting see Silva et al., this issue). By contrast, some platforms are now multi-application, but domainspecific (e.g. archaeology, Bevan et al. this issue). A challenge ahead for citizen cyberscience and, more generally, human computation will inevitably involve system interoperability. To truly reinvent discovery (Nielsen 2012), future platforms (whether citizen cyberscience or human computation) must become more discoverable, accessible, interoperable, and integrated. In this way, a free and open system of systems will begin to take shape, a path forward for easier metaanalyses will be paved, and the rate by which science can advance will be dramatically increased.

\section{ACKNOWLEDGEMENTS}

I wish to thank Pietro Michelucci for constant assistance in editing, managing, and assisting me in developing these ideas and in editing the articles for this special issue. 


\section{REFERENCES}

Estelles-Arolas, E. and Gonzalez-Ladron-de-Guevara, F. 2012. Towards an integrated crowdsourcing definition. Journal of Information Science. 38(2) 189-200. DOI: 10.1177/0165551512437638.

Haklay, M. (2013). Citizen Science and Volunteered Geographic Information - overview and typology of participation in Sui, D.Z., Elwood, S. and M.F. Goodchild (eds.) (2013). Crowdsourcing Geographic Knowledge: Volunteered Geographic Information (VGI) in Theory and Practice. Berlin: Springer. pp 105-122.

Michelucci, P. 2013a. Synthesis and Taxonomy of Human Computation. Pages 83-86 in P. Michelucci, editor. Handbook of Human Computation. Springer New York.

Michelucci, P. 2013b. Introduction. Pages 1-5 in P. Michelucci, editor. Handbook of Human Computation. Springer New York.

Newman, G., J. Graham, A. Crall, and M. Laituri. 2011. The art and science of multi-scale citizen science support. Ecological Informatics 6:217-227.

Nielsen, M. 2012. Reinventing discovery: the new era of networked science. Princeton University Press, Princeton, New Jersey.

Straubhaar, J. and LaRose, R. (2004). Media Now: Understanding Media, Culture, and Technology. Thomson Learning. p. 6. ISBN 7-302-09576-0.

Quinn, A.J. and B. B. Bederson. 2011. Human Computation: A survey and taxonomy of a growing field. CHI 2011. Vancouver BC, Canada. 